\title{
Combined Extraction of Cesium, Strontium, and Actinides from Alkaline Media: An Extension of the Caustic-Side Solvent Extraction (CSSX) Process Technology
}

\section{Final Report - Raymond Research Group}

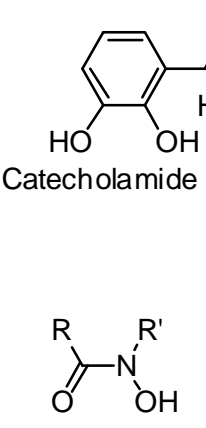

Hydroxamic acid

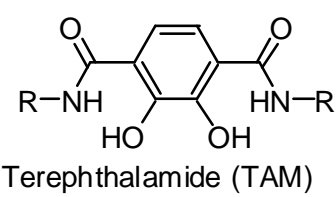

Catecholates
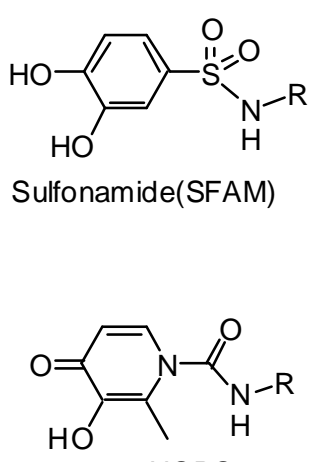

$3,4-\mathrm{HOPO}$

$$
\text { 1,2-HOPO }
$$

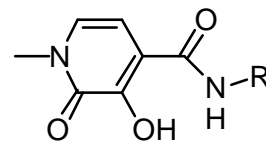

3,2-Me-HOPO

Hydroxypyridinones (HOPO)

Figure 1. Generic structures of the catecholate and hydroxamic acid derivatives used in actinide sequestering ligands developed by the Raymond Group at Berkeley.

The wastes present at DOE long-term storage sites are usually highly alkaline, and because of this, much of the actinides in these wastes are in the sludge phase. Enough actinide materials still remain in the supernatant liquid that they require separation followed by long-term storage in a geological repository. The removal of these metals from the liquid waste stream would permit their disposal as low-level waste and dramatically reduce the volume of high-level wastes. The actinide extraction and recovery systems currently in place presently are not optimal, and the alkaline conditions and presence of other radioactive metals, $\mathrm{Cs}$ and $\mathrm{Sr}$, complicate efficient extraction. The reasons for this may include the lack of data on the physical forms and properties of actinide complexes in caustic matrices. The extraction behavior of actinides in alkaline solutions has not been subjected to study, mostly because of the tendency for these elements to hydrolyze or form precipitates under these conditions. The lack of this reliable speciation data is another complication for the design of novel ligands for use in these systems. In our portion of this project, we wanted to develop new ligands for actinide extractions and develop a more fundamental understanding of the 
speciation and physical properties of actinides in complex alkaline media. This would be of tremendous benefit for additional waste remediation, storage, and decontamination technologies for dealing with these elements

The similarities in the biological and chemical behavior of $\mathrm{Fe}(\mathrm{III})$ and $\mathrm{Pu}(\mathrm{IV})$ inspired a biomimetic approach to the rational design of selective chelators for $\mathrm{Pu}(\mathrm{IV})$ based on the siderophores. ${ }^{1}$ The siderophores are Fe(III)-specific ligands are produced by bacteria to solubilize and extract Fe(III) from the environment and deliver it for use by the bacteria. ${ }^{2}$ The ligating groups found in siderophores are catecholamides, hydroxamic acids, or the related hydroxypyridinones, and have proven to be powerful and highly specific actinide(IV) sequestering agents. ${ }^{1,3,4}$ In addition to these ligands, related analogs show even greater stability - the 2,3-dihydroxyterephthalamides (TAM) ${ }^{5}$ and other non naturally occurring hydroxypyridinones (HOPO) (Figure 1). ${ }^{6,7}$ Developing these ligands for use liquid-liquid extractants is the primary goal of this work.

Preliminary investigations discussed above of derivatives of octyl-1,2-HOPO indicated that appropriate lipophilic derivatives are good candidates for further studies in basic media. The ligand 1-hydroxy-6-N-octylcarboxamide-2(1H)-pyridinone (octyl-1,2HOPO), was found to be an efficient extractant for $\mathrm{Pu}(\mathrm{IV})$ from acidic media. ${ }^{4}$ This ligand shows high specificity for $\mathrm{Pu}(\mathrm{IV})$ in the presence of $\mathrm{Na}^{+}, \mathrm{Al}(\mathrm{III})$, or $\mathrm{Fe}(\mathrm{III})$, and is able to extract $\mathrm{Pu}(\mathrm{IV})$ over a wide range of $\mathrm{HNO}_{3}$ concentrations. These results are further corroborated by two examples of $\mathrm{Pu}(\mathrm{IV})$ and $\mathrm{Pu}(\mathrm{VI})$ uptake by $\mathrm{HOPO}$ ligands attached to solid supports, ${ }^{6,8}$ and by further studies comparing the 1,2 -HOPO to its 3,2 - and 3,4 isomers. ${ }^{7}$ The results obtained in acidic solutions confirmed that the HOPO ligands are good chelators and appeared to indicate $\mathrm{pH}$ increases the ligands will only become stronger chelators because they are protic ligands. In addition, high stability constants indicated that these ligands would be well suited for complete removal of metals at dilute concentrations and in the presence of competing ligands and metals (e.g. EDTA, Al(III)). It was later found that, under the caustic conditions that one would encounter at Savannah River, the 1,2-HOPO ligands were not stable, and would decompose.

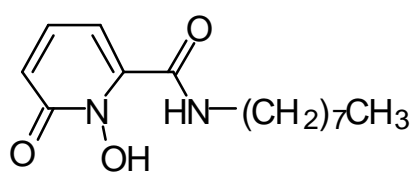

Figure 2. Octyl-1,2-HOPO 
More recently, we have started developing TAM ligands as liquid-liquid extractants. ${ }^{9}$ These ligands were found to form stable Th(IV) and Ce(IV) complexes, ${ }^{10}$ have formation constants with $\mathrm{Fe}$ (III) of $10^{45}$, and were found to be excellent chelators for $\mathrm{Pu}(\mathrm{IV})$, particularly in basic media. ${ }^{9}$ These ligands were incorporated into water-soluble chelatingpolymers, prepared as terephthalamide (TAM) functionalized polyethylenimine (PEI), for use in polymer filtration using size-exclusion ultrafiltration membrane to selectively remove actinides from dilute liquid wastes. As shown in Figure 3, this synthesis involves the asymmetric functionalization of the protected terephthalamide with N,Ndimethylethylenediamine prior to incorporation into the PEI. This addition serves to increase the solubility of the TAM ligand. Once attached to PEI, the catechol hydroxyl groups can be deprotected with $\mathrm{HBr}$ and provide the metal coordination site. ${ }^{9,11,12}$ The distribution coefficient at $\mathrm{pH} 4.5$ was found to be $1.6 \times 10^{3}$ for $\mathrm{Am}(\mathrm{III})$ and $1.3 \times 10^{6}$ for $\mathrm{Pu}(\mathrm{IV})$ and at $\mathrm{pH}$ 11.3 the distribution coefficient for $\mathrm{Pu}(\mathrm{IV}), 4.8 \times 10^{6}$, is even higher. ${ }^{9}$ These results, combined with the development of new methods for increased ease of synthesis of substituted TAM ligands, ${ }^{11}$ provided further support for our optimism that a combined process incorporating one of these strong and selective ligands for actinides with those selective for strontium and cesium could be developed. Based on the differences in their properties, it was not expected that strontium and actinides could be extracted by a single ligand, a combination of two ligands or serial extractions was an alternative method.

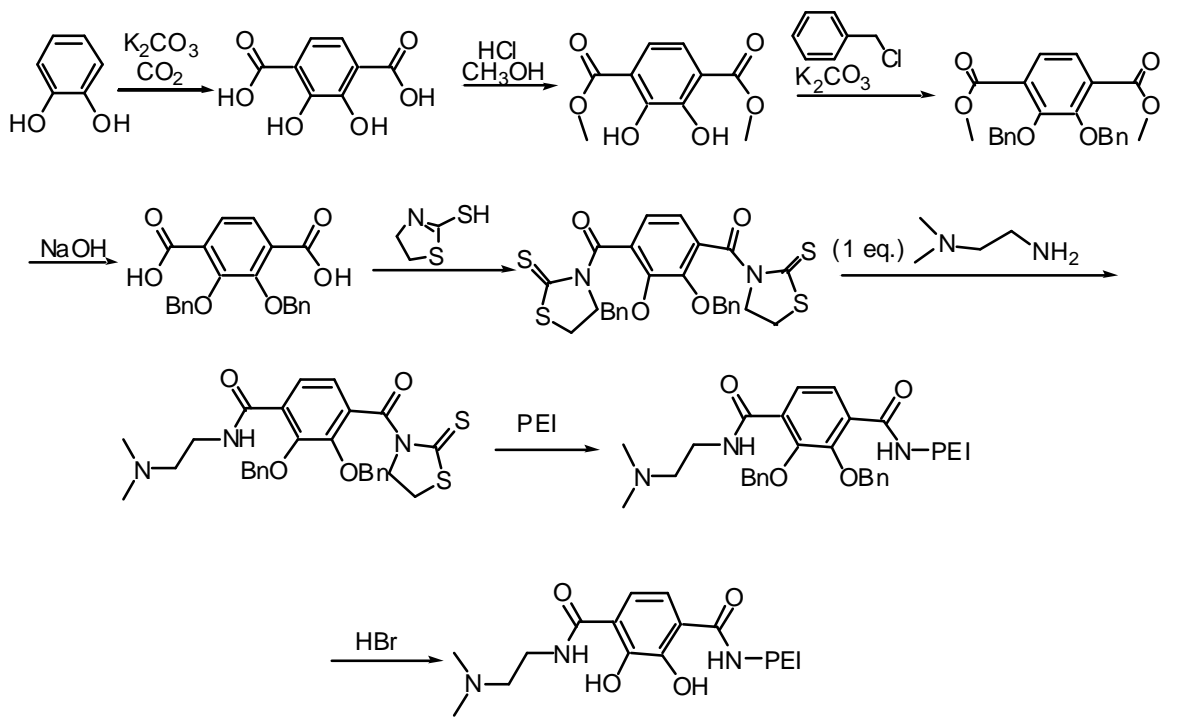

Figure 3. Synthesis of PEI supported water-soluble polymers 


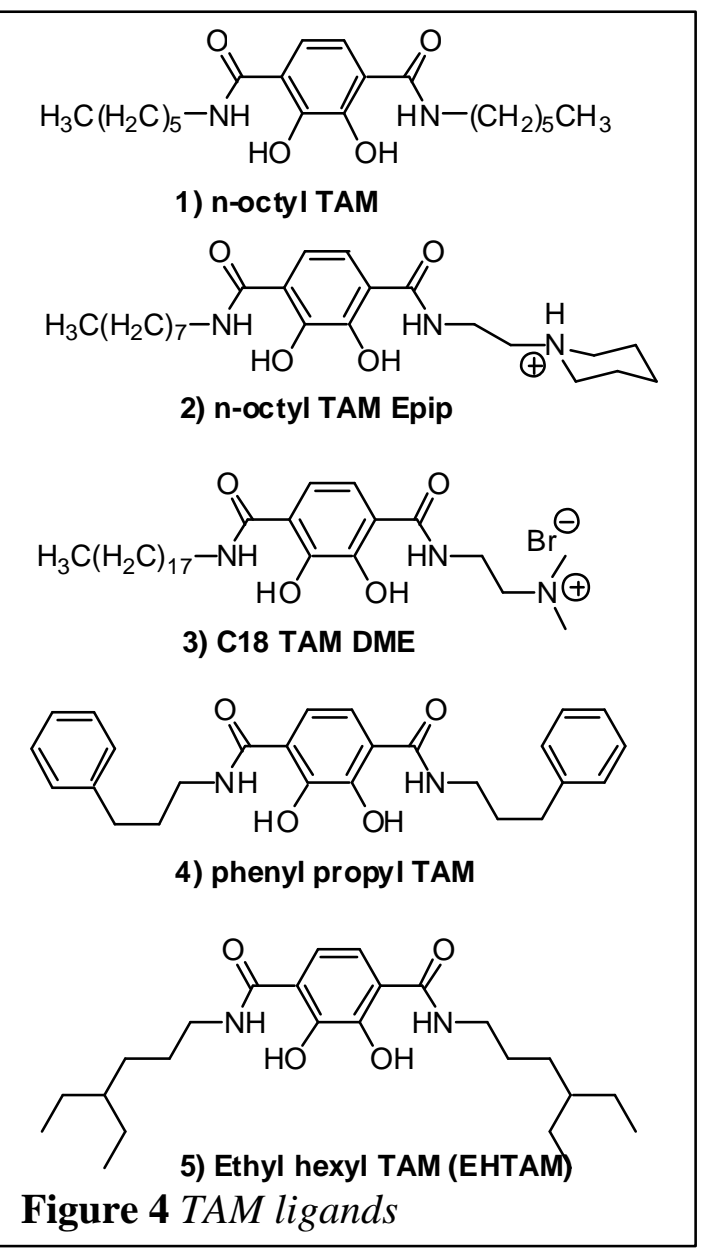

In Table 1 the overall stability constants $\left(\beta_{140}\right) \quad$ for the formation found using spectrophotometric titrations for some of these ligands is shown. The overall stability constant $\left(\beta_{140}\right)$ of the $\mathrm{Pu}(\mathrm{HOPO})_{4}$ complex is estimated to be $10^{47}$ based on the stability of the $\mathrm{Ce}(\mathrm{HOPO})_{4}$ complex. These high stability constants manifest themselves in two important ways: these ligands should prevent metal hydrolysis and precipitation at high $\mathrm{pH}$, and they are capable of sequestering metals that are present in low concentrations. The $\mathrm{pM}$ values appear to indicate some selectivity for the actinides over cerium. A few bidentate TAM ligands with lipophilic solubilizing substituents were prepared for study.

Because the coordination of four of these ligands to $\mathrm{Pu}(\mathrm{IV})$ or $\mathrm{Th}(\mathrm{IV})$ results in an anionic complex, ${ }^{10,11}$ initially two strategies to form neutral complexes were pursued to facilitate extraction into an organic phase. These were: 1) incorporation of a positively charged substituents into one of the ligand side arms will result in a neutral metal complex, and 2) a lipophilic counter-cation in addition to a lipophilic TAM ligand will permit extraction into the organic phase as an ion co-pair. The variation of the side chain will permit the solubility of the ligands to be tailored for different solvents. The approach using a symmetrically modified ligand with alkylated counter cation is highly promising for several reasons. Cetylpyridinium is inexpensive and commercially available. In addition, a variety of ammonium and phosphonium salts are available that may help tailor the solubility of the resultant metal complex in different extraction solvents.

\begin{tabular}{|ccccccc|}
\hline $\begin{array}{c}\text { Log } \\
\text { Kmlh }\end{array}$ & $\begin{array}{c}\text { Tiron } \\
\text { Ce(IV) }\end{array}$ & $\begin{array}{c}\text { Tiron } \\
\text { Th(IV) }\end{array}$ & $\begin{array}{c}\text { HOPO } \\
\text { Ce(IV) }\end{array}$ & $\begin{array}{c}\text { HOPO } \\
\text { Th(IV) }\end{array}$ & $\begin{array}{c}\text { ETAM } \\
\text { Th(IV) }\end{array}$ & $\begin{array}{c}\text { ETAM } \\
\text { Pu(IV) }\end{array}$ \\
\hline $\log \beta 140$ & 56.5 & 58.7 & 39.5 & 42.6 & 45.6 & 55.6 \\
pM & 32.0 & 34.4 & 28.4 & 30.8 & 33.2 & 43.7 \\
Table 1. & & & & & & \\
\hline
\end{tabular}




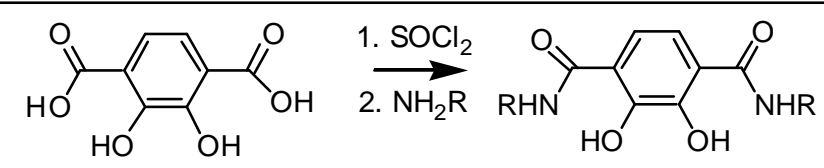

Figure 5a.
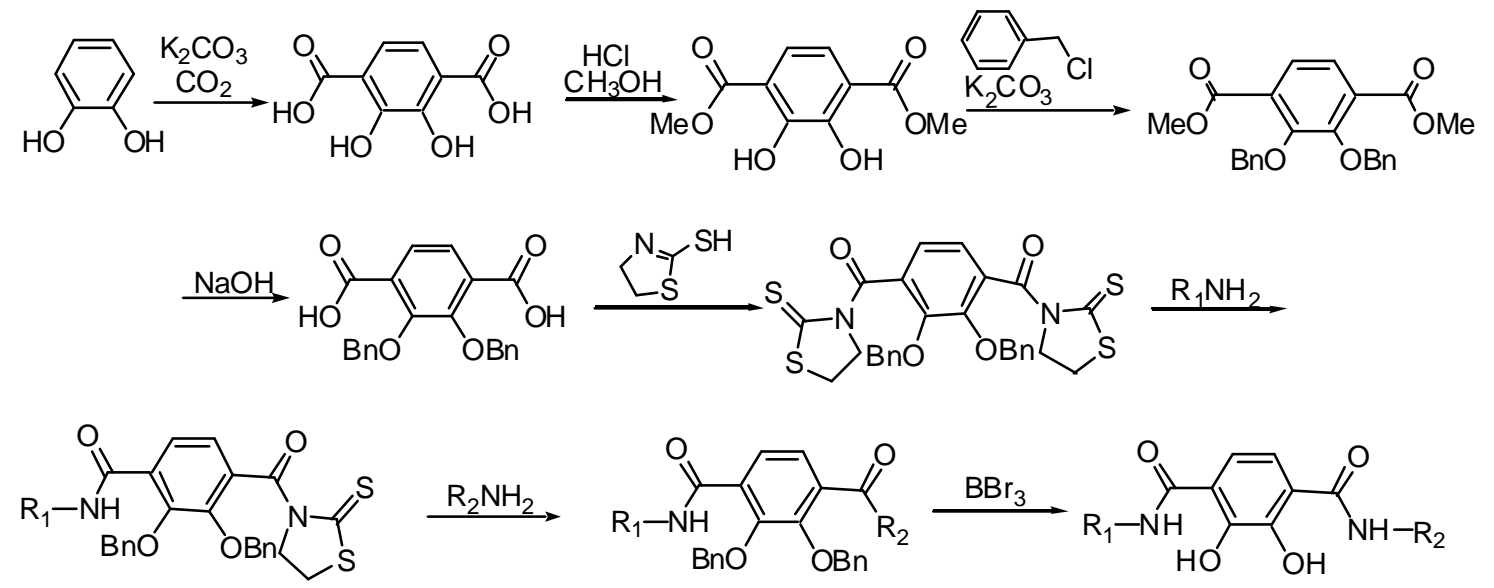

Figure 5b.

Toward this end, a series of terephthalamide ligands containing both charged and neutral species was prepared for testing in extraction studies (Figure 3). It was found that the new method of "one-pot" synthesis (Figure 4b) for symmetric ligand did not always work for ligands with these types of lipophilic solubilizing groups, ${ }^{11}$ resulting in poor yields, hence the standard synthesis previously used (Figure 5) was preferred..$^{5}$ Two of these TAM ligands ( $\mathrm{R}=$ n-octyl $(\mathbf{1})$ and $\mathrm{R}=$ phenylpropyl (2)) have been tested by solvent extraction (1-octanol, $10 \mathrm{mM})$. The observation of precipitation of actinides during the extraction indicated a new procedure involving preliminary centrifugation was required. Because of these solubility problems, these results appeared to indicate that, although TAM ligands are strong actinide sequestering agents, the bidentate ligands would not be the optimal extraction agents for this application; however, in the case of the ethyl hexyl TAM ligand, the solubility characteristics were improved enough to demonstrate effective extraction characteristics for both the actinides and Sr. What was also found in these studies was that, although useful extraction was being achieved, the ligands were found to decompose at this caustic pH. The TAM ligands shown high affinity towards actinide ions, they are easily get oxidized at high $\mathrm{pH}$ under aerobic conditions.

Efforts were made to search other suitable candidate ligand systems. There are several possible choices: (1) additional substituted TAM ligands (2) Catechol mono- and disulfonamide ligands (3) HOPO ligands including 1,2-HOPO, 3,2-HOPO and 3,4-HOPO 


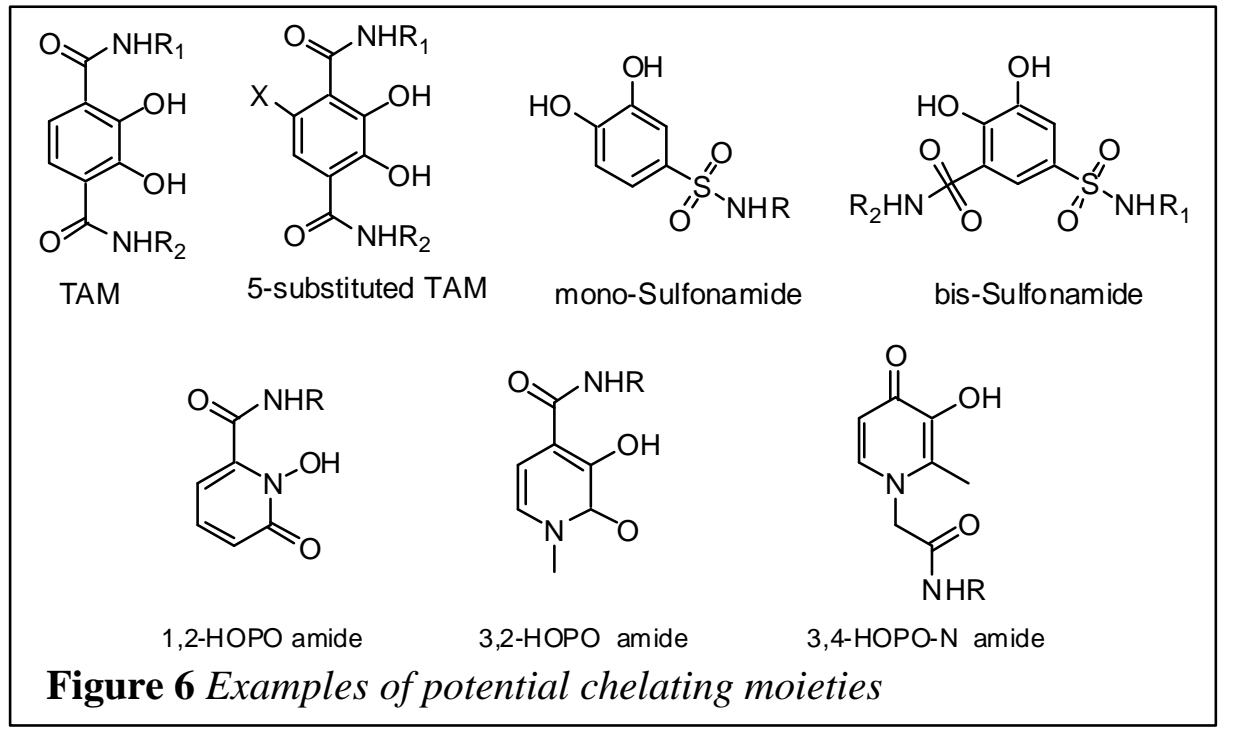

ligands (Figure 5).

The introduction of

a chloro- or other

electron with

drawing group

onto the TAM

aromatic ring may

make the TAM

ligand more

resistant towards

oxidation, but the

effect may be limited, and efforts toward a 5-substituted nitroso-TAM have proven very synthetically challenging. The catechol mono-sulfonamides are oxidized quickly at high pH in the air. The catechol bis-sulfonamides are derivatives of Tiron, while they should be resistant enough towards oxidation at high $\mathrm{pH}$, the primary sulfonamide protons are quite acidic, therefore the bis-sulfonamide would be quite water soluble and may not be suitable for the purpose of liquid-liquid extraction. In addition there is no such compound reported in literature, and this too, has proven a unique synthetic challenge.

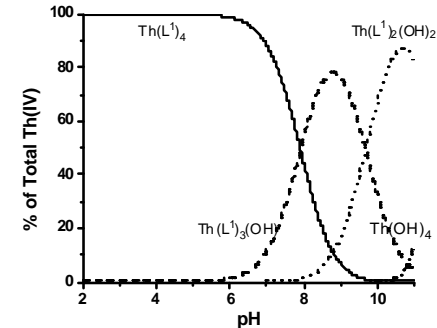

Th(IV)-PR-1,2-HOPO System

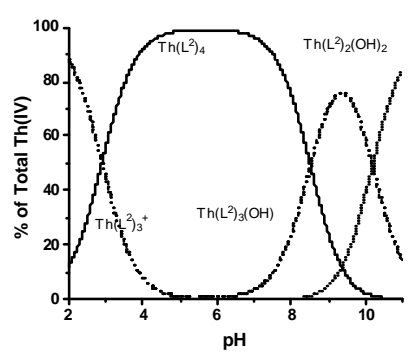

Th(IV)-PR-3,2-HOPO System

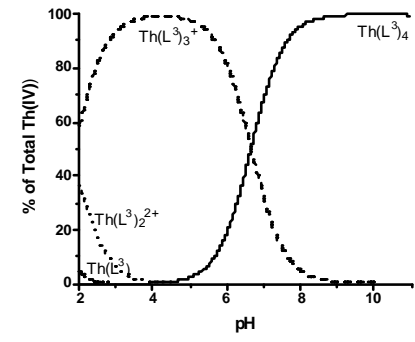

Th(IV)-PR-3,4--HOPO-N System Figure 7. Comparison of hydrolysis over a wide $\mathrm{pH}$ range for several HOPO ligands based on calculation from pKas.

The amides of 1,2- and 3,2- HOPOs have previously been demonstrated to be quite good liquid-liquid extraction agents in the ranges of low and physiological pHs. The 3,4HOPO-N ligands have not been shown as good an extraction agent in the acidic or neutral $\mathrm{pH}$ range; however, titration simulation calculations indicate that the 3,4-HOPO-N ligands could be promising extractants in this high $\mathrm{pH}$ range (Figure 6). Preliminary testing indicated that the pure PR-3,4-HOPO-N ligand can survive from the basic condition $(3 \mathrm{M} \mathrm{NaOH}+10 \mathrm{M}$ 
$\mathrm{NaNO}_{3}$ ) for a period of time; however 3,4-HOPO-N ligand moiety is more polar than that of 3,2-HOPO and 1,2-HOPO, therefore additional lipophilic R- groups need to be used to generate effective liquid-liquid extraction properties. The new C18-3,4-HOPO-N has been prepared and was ready for testing in extraction model systems (Figure 8.)

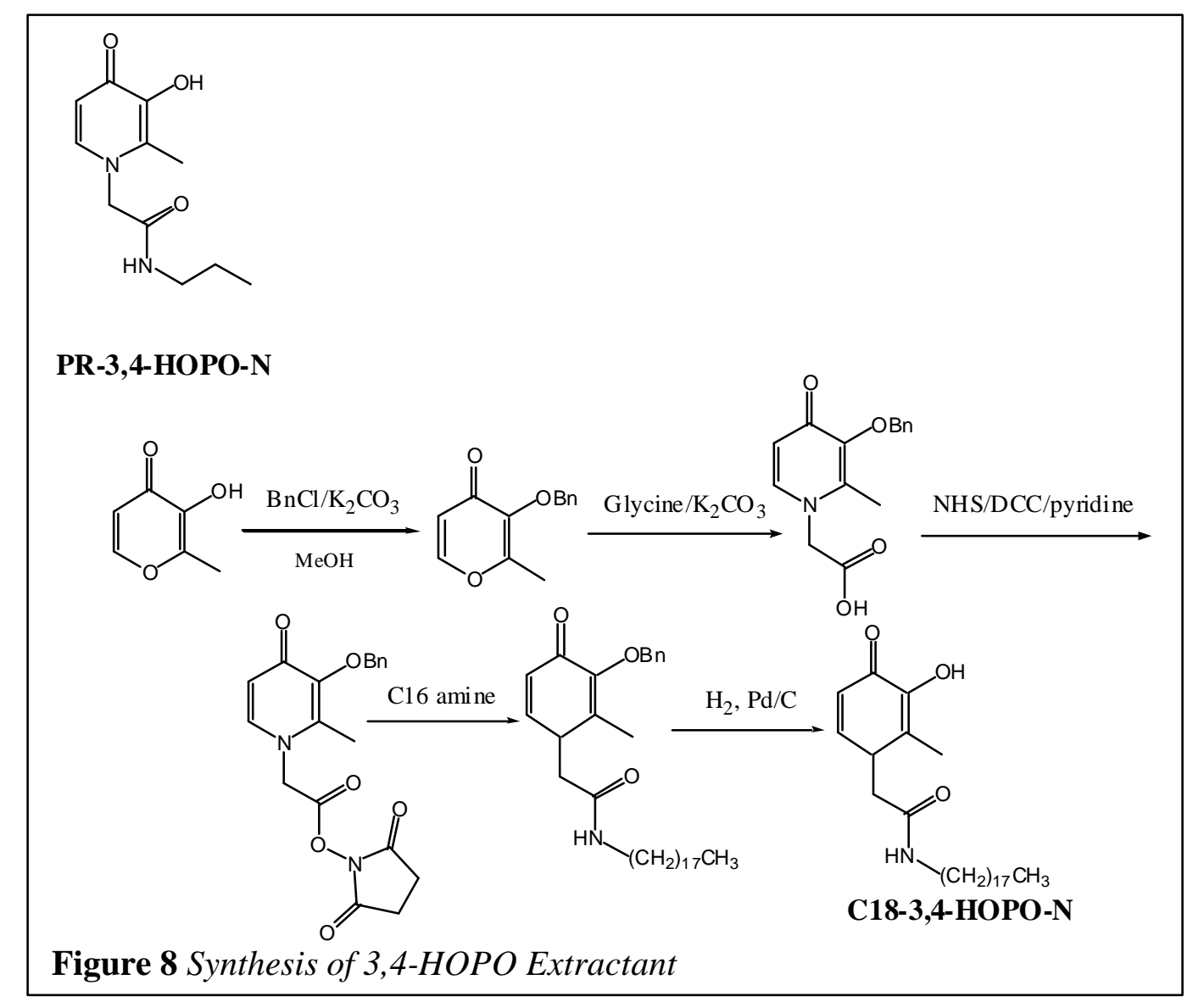

The first task presently at hand is the evaluation of the C18-3,4-HOPO-N ligand (Figure 8) recently prepared as an extractant and the identification of the mechanism. Concurrently, we would want to identify the mechanism of decomposition and decomposition products of the TAM and SFAM ligands at caustic $\mathrm{pH}$. The decomposition of the TAM is most likely due to either hydrolysis of the amide functionality or of the ring itself. The hydrolysis mechanism and products could hopefully be determined either through a batch titration with $\mathrm{NaOH}$ and isolation and identification of the products, or through NMR titrations. Given our recent success with TAM as an extractant for $\mathrm{Sr}$, we may also choose to follow up on this by characterizing ligands in solution with this metal. Also of interest would be the structural characterization of these ligands with actinides and actinide analogues, as it would provide insight into the coordination behavior and fundamental chemistry of the 
metal. This information will better equip us to address some the fundamental issue surrounding the practical problems of radioactive waste remediation. ${ }^{13}$ This work is the subject of ongoing investigations.

\section{REFERENCES}

(1) Gorden, A. E. V.; Xu, J.; Raymond, K. N.; Durbin, P. W. Chem. Rev. 2003, 103, 4207 - 4282.

(2) Stintzi, A.; Barnes, C.; Xu, J.; Raymond, K. N. Proc. Natl. Acad. Sci. USA 2000, 97 , 10691-10696.

(3) Romanovski, V. V.; Whisenhunt Jr., D. W.; Veeck, A. C.; Andersen, R. A.; Hoffman, D. C.; Xu, J.; White, D. J.; Raymond, K. N. In International Topical Meeting on Nuclear and Hazardous Waste Management; American Nuclear Society, LaGrange Park, IL: Seattle, Washington, 1996; Vol. 3, pp 2330-2334.

(4) Romanovski, V. V.; White, D. J.; Xu, J.; Hoffman, D. C.; Raymond, K. N. Solv. Extr. Ion Exch. 1999, 17, 55-71.

(5) Garrett, T. M.; Miller, P. W.; Raymond, K. N. Inorg. Chem. 1989, 28, 128-133.

(6) Zhao, P. H.; Romanovski, V. V.; Whisenhunt, D. W.; Hoffman, D. C.; Mohs, T. R.;

Xu, J. D.; Raymond, K. N. Solv. Extr. Ion Exch. 1999, 17, 1327-1353.

(7) Veeck, A. C.; White, D. J.; Whisenhunt Jr., D. W.; Xu, J.; Gorden, A. E. V.;

Romanovski, V.; Hoffman, D. C.; Raymond, K. N. Solv. Extr. Ion Exch 2004, 22, $1037-$ 1068.

(8) Feng, X.; Rao, L.; Mohs, T. R.; Xu, J.; Xia, Y.; Fryxell, G. E.; Liu, J.; Raymond, K. N. In Environmental Issues and Waste Management Technologies in the Ceramic and Nuclear Industries IV; Marra, J. C., Chandler, G. T., Eds.; The American Ceramic Society: Ohio, 1999; Vol. 93, pp 35-42.

(9) Gramer, C. J.; Raymond, K. N.; Jarvinen, G. D.; Schroeder, N. C.; Robison, T. W.; Smith, B. F. Sep. Sci. and Technol. 2003, 39, 321 - 339.

(10) Gramer, C. J.; Raymond, K. N. Inorg. Chem. 2004, 43, 6397 - 6402.

(11) Gramer, C. J.; Raymond, K. N. Org. Lett. 2001, 3, 2827-2830.

(12) Gramer, C. J. In Department of Chemistry; University of California: Berkeley, 2001.

(13) Clark, D. L.; Hobart, D. E.; Neu, M. P. Chem. Rev. 1995, 95, 25 - 48. 